\title{
Understanding Likes on Facebook: An Exploratory Study
}

\author{
Anita Basalingappa. MICA, Ahmedabad, India \\ M S Subhas, Karnatak University, India \\ Ms Rashmi Tapariya, MICA, Ahmedabad, India
}

\begin{abstract}
This study focuses on understanding 'likes' on facebook. It is important to understand this phenomenon by studying how users would react to a post that is posted by a 'friend'. Therefore, the objective of this paper is to understand what does it mean to 'like' a post on facebook? Is there a preference for a picture post in a status update than the written word? Are there distinctive types of 'likes' that can be useful to understand 'likes' on facebook? This is an exploratory study. Data was collected through Depth interviews and observing Facebook profiles. Twelve depth interviews were conducted and thirty nine facebook profiles' data was observed from August 2013 to August 2014. The results show that profile pictures get maximum likes followed by status updates and then cover photos. The respondents indicated a pattern in the likes on each post.
\end{abstract}

Keywords: social media, Facebook, like 


\section{Introduction}

Social media has become a power house as it provides for a democratic relationship. There is a need to understand this medium and its users on a continuous basis. Every new invention is a boon and a bane. Likewise, social media is one such powerful tool in marketing that is a boon and bane. Social media is clearly a boon because it is cheaper, faster and wider in its reach with added real time interactions. Everything is instant and it is enticing, new and generates excitement: whereas the same social media can be utilised cleverly to mislead masses. The speed at which one can be informed/misinformed, persuaded, impressed and form opinions through social media is scary. One can only repent later if there are no checks and balances.

Two most popular social media tools, 'Facebook' and 'Twitter' were launched in February 2004 and July 2006 respectively. There were 1.28 billion facebook users in 2013 (Facebook statistics, 2014) and 0.65 billion twitter users in 2014 (Twitter statistics, 2014) worldwide. India has the second highest number of facebook users in the world according to Smith (2014) with 100 million facebook users and fifth largest twitter user (33 million twitter users) according to an exhaustive study on twitter user across the world (2012).

There is a lot of attention on number of likes and favourites, shares and retweets for celebrities and their comments and status updates in social media. Do more likes and favourites indicate higher value, popularity, success and vice versa? There seems to be such a perception, rather conviction among users. Number of likes on facebook is an important metric. There are formulae to calculate value of a 'like'. There are papers on why does one 'like' a post. Most of these are in the context of brands and corporate where the facebook accounts are moderated and promoted by designated employees or outsourced.

Each user on facebook is an influencer for other users. There is a need to understand liking of facebook users' posts by other users on facebook. For brands, higher the volume of likes, higher is the value (O'Connor, 2013). Is it the same for a user who is an influencer? Is the facebook user, who gets more 'likes' for his/her posts, more influential than a person who gets fewer 'likes'? Are there other factors dominating the value of a 'like' of each user?

This paper focuses on Facebook 'likes' between friends on facebook. It is important to understand why 'like' a post. It is important to understand this phenomenon by first studying 
how users would react to a post that is posted by a 'friend'. Therefore, the objective of this paper is to understand what does it mean to 'like' a post on facebook? Is there a preference for a picture post in a status update than the written word? Are there distinctive types of 'likes' that can be useful to understand 'likes' on facebook?

\section{Literature Review}

'Friend' (n.d.) as a noun is a person known well to another and regarded with liking, affection, and loyalty; an intimate; an acquaintance or associate; an ally in a fight or cause; supporter; a fellow member of a party, society, etc; a patron or supporter: a friend of the opera; be friends, to be friendly (with); make friends, to become friendly (with). As a verb, 'friend' (n.d.) to add (a person) to one's list of contacts on a social-networking website; befriend. Facebook glossary of terms, defines friends as people you connect and share with on Facebook.

'Like' (.n.d.) is used as a noun, verb, and adverb on social mediato indicate one's enjoyment of, agreement with, or interest in. noting or pertaining to a feature used to like specific website content: a Like button. The glossary of terms on facebook help center includes the words: profile, profile picture, cover photo, and timeline. These key words will be used in this paper. A facebook user can post pictures and comment on his/her profile. A facebook user's profile is a collection of the photos, stories and experiences that tell his/her story. Timeline is where the user can see his/her posts or posts where he/she has been tagged in, displayed by date. Timeline is also part of the user's profile. Profile picture is the main photo of the facebook user on his/her profile. The profile picture appears as a thumbnail next to the user's comments and other activity on Facebook. Cover photo is the large picture at the top of the user'sprofile, right above the profile picture.

'Like' button feature on facebook was introduced to 'like' status updates, photos, shares and comments of friends (Kincaid, 2009). This feature, with an option to the user to like or not like was introduced to express 'like' or support the post. The number of 'likes' and the identity of each user who has liked the post are visible for each facebook post. When the user clicks the 'like' button, that post appears in the user's newsfeed, and is visible to user's friends. According to Glossary of terms on facebook, clicking Like is a way to give positive feedback and connect with things you care about. 
Every page visited on internet is stored in cookies. Number of 'click throughs' has been a metric used to assess 'reach' on social media. Facebook 'likes' data is richer than 'click throughs' as it indicates positive feedback of the users who have liked the post. Definitely, 'share' option and 'comments' are richer than 'likes' since it captures users' intention more than a 'like'. It is seen that it is easiest to hit the 'like' button for a post or a comment than the other options apart from not doing anything. Could the responses be any different if facebook had a semantic differential scale instead of just a 'like' option? It is useful to understand why most users like a post or a comment.

There have been many studies on why users like facebook pages/posts of brands. Common shared values with brand and to keep a check on recent updates/products of a brand as it would appear in news feed once its page has been liked (Pelletier \& Horky, 2013); Genuine preference for the brand or brand loyalty towards the brand (Wallace et al., 2014); Satisfactory performance of the brand though not being brand loyalist (Bunker et al., 2013); Interest in discounts offered, freebies, special offers (Murthy et al., 2013); Image Building - Engaging in image development by letting others know that one follows/ prefers a particular brand which would not have been possible to showcase in offline manner. More often such people are concerned about others viewpoint (Bunker et al., 2013); Brand being promoted by favourite actor/actress (Budhiraja \& Mhatre, 2011); Liking a post as it has been liked by one of the friends who shares common belief system (Lipsman et al., 2012); TV Channels promoting online chat shows/ online videos / content (Budhiraja \& Mhatre, 2011) are some of the reasons why people tend to like facebook posts/ pages of brands.

Users also tend to like facebook posts of other users if the post/ content carries similar brand/ personal experience, for social acceptance as the post has been liked by some of the members of the social group one belongs to, or just displaying belongingness - to let them know that one is concerned about others and their lives (Shoenberger \& Tandoc, 2014). A study published in Communication Briefings (2013) showed that users who post content on facebook that is humorous, exciting, engaging, and/ or thrilling will receive more likes. It is also evident that, inspiration as content, showcasing brave, real life stories of real persons, increased number of likes. Liking a post as it has been liked by like-minded people in one's facebook friend list (Lipsman et al., 2012) is also another reason.Mariani and Mohammed (2014) found that the convenient facebook like button is a social endorsement influencing brand recall and future 
purchase intentions. Therefore, the studies above establish that a facebook like is an important metric for brands and marketers. Studies have shown different types of fan behaviour on facebook (Wallace et al., 2014).

The engagement of users on facebook is key to success of a like. The engagement of facebook users is through consumption of the social space on facebook. Why do facebook users post pictures and comment on facebook? What generates more likes - profile picture, cover photo, pictures on timeline or text on timeline?

Therefore, research questions for the paper are:

1) Why does one 'like' a profile picture, cover photo or a post on timeline/ status update on facebook?

2) What gets more 'likes': profile picture, cover photo, or post on timeline/ status update? And why?

3) What are the different types of likes? Are there a standard proportion of types of likes for each post?

\section{Methods}

This is an exploratory study to understand 'likes' on profile picture, cover page and status update of individual facebook users. Each respondent in this study is a facebook user below 35 years age, who has been active on facebook in the last two years and is a graduate with more than 200 friends on facebook. "Active on facebook" is defined by frequency of posts and time spent on facebook every week. Respondents for this study were recruited if they posted 3 to 4 posts every week and spent an average of 20 minutes everyday on facebook.

Methodological triangulation is used to crosscheck information to produce accurate results for certainty in data collection. Data collection was through two methods. Twelve depth interviews were conducted. Thirty nine facebook profiles were monitored for a period of one year from August 2013 to August 2014. The facebook profiles of respondents were monitored through 'Liken Tweet', a facebook profile created to study the posts and likes of friends. Facebook users with at least 200 facebook friends, below the age of 35 years wereinvited to volunteer to be respondents. The respondents were invited by sending out inbox requests to friends on facebook and via email to the student group of a post graduate management institute. Thirty 
nine respondents become friends with Liken Tweet. The thirty nine facebook profiles were accessed to collect data on posts and likes on their profile posts, cover photo posts and status update on timeline from August 2013 to August 2014.Of the twelve respondents who were interviewed, six respondents were not friends on Liken Tweet. Therefore, total of 45 respondents were interviewed and observed (with six of respondents who were both interviewed and profiles monitored on Liken Tweet).

The respondents' profile is as in the table below:

Table 1. Profile of respondents

\begin{tabular}{|c|c|c|}
\hline & Depth Interviews & Friends on Liken Tweet \\
\hline Number of respondents & 12 & 39 \\
\hline Total Respondents & & $45^{*}$ \\
\hline \multicolumn{3}{|l|}{ Age } \\
\hline $16-20$ & 0 & 1 \\
\hline $21-25$ & 9 & 26 \\
\hline $26-30$ & 3 & 12 \\
\hline \multicolumn{3}{|l|}{ Marital Status } \\
\hline Single & 11 & 35 \\
\hline Married & 1 & 4 \\
\hline \multicolumn{3}{|l|}{ Occupation } \\
\hline Employed & 7 & 18 \\
\hline Home maker & 0 & 2 \\
\hline Student & 5 & 19 \\
\hline \multicolumn{3}{|l|}{ Gender } \\
\hline Man & 5 & 20 \\
\hline Woman & 7 & 19 \\
\hline \multicolumn{3}{|l|}{ Education } \\
\hline Undergraduate & 2 & 6 \\
\hline \multicolumn{3}{|l|}{ Postgraduate } \\
\hline (completed/studying) & 10 & 33 \\
\hline \multicolumn{3}{|l|}{ Year of joining facebook } \\
\hline $2007-2010$ & 10 & 38 \\
\hline $2011-2013$ & 2 & 1 \\
\hline \multicolumn{3}{|c|}{ Number of facebook friends } \\
\hline upto 1000 & 9 & 15 \\
\hline $1000-2000$ & 3 & 10 \\
\hline$>2000$ & 0 & 1 \\
\hline Data not available & 0 & 13 \\
\hline
\end{tabular}

*6 of the respondents Depth Interviewed were not friends on Liken Tweet 
The average age of respondents was 25 years. Most of them were single. Fifty percent of the respondents were students and the rest were employed. All of them were at least undergraduates. There was a fair representation of men and women in the sample. Some of the respondents had blocked their facebook joining date and number of facebook friends through their privacy settings.

\section{Findings}

\section{Research Question 1:}

Why does one 'like' a profile picture, cover photo, or a post on timeline/ status update on facebook?

A post on facebook asking users: "What does one indicate through a like on a facebook post? Acknowledge? Like (verb)? Fan? Love? Advocate? Friend? share on newsfeed? wants to keep a tab?" got the following responses:

Q Quid pro quo! You dint like my post, I won't like yours

co All of the above

@ Approve, have been through that, appreciation, jealousy (since you are trying so hard let me give you one 'like')

@ Approval, personal preference or endorsement

@ A great discovery for the linguistically challenged

$\propto$ It is for the post-er to decipher

\& Many likes as a way to get more likes in return and feel great about one's self. \& Say 'you are connected' without actually bothering to see/read what the other person has posted

\& I'm there

@ I like YOU

$\infty$ Younger crowd may also use it as a gesture of group affiliation reinforcing affiliation and friendship

$œ$ 'main hu na' meaning - I am there for you.

From the literature, facebook likes indicate the following:

@ Following someone seriously and making presence felt

@ More likes, more loved /recognized the person is

@ Respect/Love for the person who has posted 
@ Oblige the person who has posted (friends/ Relatives)

$@$ Time pass i.e. like the pictures which comes across once one is logged in

\& Motivate/ appreciate the person to repeat the activity

œ Appreciate someone else's sense of humor

@ Reciprocation/ Mutual admiration

$\infty$ Way to stay connected to the person/ social belongingness

@ Like reveals one's interests to other friends in the friend list

@ Repeatedly the post comes in notification box

@ Supporting the cause/ shared content even when the person who has shared is not a close friend or acquaintance

\& When the content is Unique/ interesting/ Social cause/ emotionally appealing/ cultural issues/ religious issues

$œ$ Considered a replacement of face to face meeting i.e. when a person is unable to meet an old friend on a regular basis then liking a post of them means the person still follows and is in the loop.

From the depth interviews:

@ To stay connected to person, to avoid commenting so hit like to show that I like the person, if other person has liked then even I will like, Feel good factor for others

\& Good videos, interesting ads, good intelligent articles, related to personal likes/ dislikes

$\propto$ Out of courtesy, Reciprocity, Interesting(funny), different or something unusual, news getting married, birthdays, events; mandatory/out of courtesy for close friends/colleagues

œ Profile picture like; something related to personal taste eg. bikes; related to mood and emotions; marriage; awards; achievements

$\infty$ If I can relate to what is there in status then I would like their status; or if I can emotionally attach myself be it a picture or status.

The reasons for likes on facebook can be explained using need for association. Liking a post might satisfy safety needs, belonging needs and/or self esteem needs from hierarchy of needs, Maslow (1943). Liking posts on facebook does not follow the sequence as in Maslow's hierarchy of needs. Nain (2013) explain a series of needs that can be used to understand the reasons for liking posts from the findings of this study. 


\section{Research Question 2:}

What gets more 'likes': profile picture, cover photo, or post on timeline/ status update? And why?

Most of the respondents said that profile picture gets more likes compared to cover photo and status updates on timeline. The Table 2 below has a list of types of posts across profile picture, cover photo and status updates. Table 3 shows possible reasons why these posts get likes according to respondents interviewed.

Table 2. Types of posts across profile picture cover photo and status updates

\begin{tabular}{|l|l|l|}
\hline Profile Pictures & Cover Photos & Status Updates \\
\hline Personal pictures & Personal Events & Personal Activities \\
\hline Adventurous & Professional Events & Professional Achievements \\
\hline likes/dislikes & Personal tastes & Favourite Brand Posts \\
\hline Posing differently & Likes/Dislikes & Interesting \\
\hline Life Updates & Poster type pictures & Funny \\
\hline Marriage pictures & Family pictures & Posts with Pictures \\
\hline Travelling & Personality Linked & Politics \\
\hline Awards & Adventurous & Travel Updates \\
\hline Fashionable & Scenic Beauty & Emotions \\
\hline Emotional & Motivational & Knowledgeable \\
\hline Child Birth & Aspirational & Catchy /precise activities \\
\hline Sentimental Posts & Leadership & Socio Political \\
\hline Close Friends picture & Long Shot & Controversial Updates \\
\hline Interesting & Colorful & \\
\hline Unique & Cartoons & \\
\hline Sweet Click & Quotes & \\
\hline Funny & Themes & \\
\hline Exclusive & & \\
\hline Beautiful/Handsome & & \\
\hline Current Clicks & & \\
\hline Close-up & & \\
\hline Scenic Beauty & & \\
\hline
\end{tabular}


Table 3. Reasons for liking a post

\begin{tabular}{|l|}
\hline Image Change \\
\hline Reciprocity \\
\hline Genuinely liking me \\
\hline Unexpected picture \\
\hline Obligated to like \\
\hline Feel Good Factor \\
\hline To Stay Visible \\
\hline Out of Boredom \\
\hline People with few friends \\
\hline Close Friends/Relatives/People interacting daily \\
\hline Emotional Connect \\
\hline Attractive/Appealing \\
\hline Beautiful \\
\hline Strong Bonding \\
\hline Trip Related \\
\hline Recently like friend \\
\hline
\end{tabular}

Table 4. The types of posts that get maximum likes in descending order

\begin{tabular}{|l|}
\hline Posing Differently \\
\hline Funny \\
\hline Close Friends/Relatives/People interacting daily \\
\hline To stay Visible/ connected \\
\hline Interesting \\
\hline Likes/Dislikes \\
\hline Genuinely liking me \\
\hline Reciprocity \\
\hline Unexpected/something unusual \\
\hline Marriage Clicks \\
\hline Feel Good Factor \\
\hline Emotional Connect \\
\hline Scenic Beauty \\
\hline Fashionable \\
\hline Appealing \\
\hline Travelling \\
\hline Scenic Beauty \\
\hline Knowledgeable \\
\hline Personal Activities \\
\hline Professional Achievements \\
\hline Obligation \\
\hline
\end{tabular}


Table 4a shows types of posts that get maximum likes according to the respondents who were interviewed and their facebook profiles observed through Liken Tweet.

Table 4a. Per cent of likes for types of posts

\begin{tabular}{|l|l|}
\hline Types of Posts & Maximum Likes in \% \\
\hline Popular & 58 \\
\hline Influencial & 48 \\
\hline Interesting & 42 \\
\hline Intelligent & 41 \\
\hline Unique & 35 \\
\hline Funny & 26 \\
\hline Trivial & 25 \\
\hline Pretty & 22 \\
\hline Emotional & 14 \\
\hline
\end{tabular}

The data from facebook profiles:

The Table 5 below shows average posts, standard deviation, average maximum likes and average minimum likes across profile pictures, cover photos and status updates per user. Most of the facebook users get maximum likes for profile pictures, followed by status updates and cover photos. The number of posts by facebook users is highest for status updates followed by profile pictures and cover photos. 
Table 5. Number of posts and likes per user across profile picture, cover photo and status update

\begin{tabular}{|l|r|r|r|r|}
\hline & Average & Standard deviation & Maximum & Minimum \\
\hline Profile pictures per user & 12 & 18 & 100 & 0 \\
\hline Average profile pictures per & & & & \\
user\% & 11 & 15 & 74 & 0 \\
\hline Maximum likes & 120 & 76 & 272 & 0 \\
\hline Minimum likes & 36 & 52 & 272 & 0 \\
\hline Likes as a \% of friends & 13 & 9 & 33 & 0 \\
\hline Cover photos per user & 7 & 8 & 43 & 0 \\
\hline Average cover photos per user \% & 6 & 7 & 30 & 0 \\
\hline Maximum likes & 63 & 67 & 248 & 0 \\
\hline Minimum likes & 7 & 17 & 100 & 0 \\
\hline Likes as a \% of friends & 7 & 7 & 20 & 0 \\
\hline Status updates per user & 136 & 115 & 594 & 4 \\
\hline Average number of updates per & 84 & 20 & 100 & 13 \\
user \% & & & & 7 \\
\hline Maximum likes & 93 & 55 & 241 & 0 \\
\hline Minimum likes & 0 & 2 & 8 & 1 \\
\hline Likes as a \% of friends & 11 & 5 & 23 & \\
\hline
\end{tabular}

\section{Research Question 3}

What are the different types of likes? Are there a standard proportion of types of likes for each post?

Each of the facebook users interviewed could identify a pattern of likes on posts. Table 6 shows some of the responses of respondents. 
Table 6. Generalisable types of likes identified by facebook users across profile picture, cover photo and status update posts

\begin{tabular}{|l|}
\hline $\begin{array}{l}\text { Amongst the likes on your facebook posts, can you differentiate between likes on } \\
\text { various posts? How?? Is there a pattern of like seen on each post?? Is it the same or } \\
\text { different? }\end{array}$ \\
\hline Reciprocity, Feel good factor, attracted towards me, Genuinely like you, Family friends \\
\hline $\begin{array}{l}\text { New picture then batch mates would like more. If post carries intelligent ad/ article } \\
\text { then random people would like because of genuine reasons, just to stay connected } \\
\text { There is a difference in liking pictures and difference in posting ads/articles }\end{array}$ \\
\hline $\begin{array}{l}\text { Same proportion. Reasons are family members; close friends, colleagues; } \\
\text { acknowledgment; sort of connect/stay connected }\end{array}$ \\
\hline $\begin{array}{l}\text { Same pattern. It is different in the case when profile picture includes someone else also i.e. } \\
\text { tagged photograph }\end{array}$ \\
\hline Same Proportion ( Likes from Close friends, To stay connected) \\
\hline $\begin{array}{l}\text { Yes I feel the proportion is same. } 20 \% \text { likes are from family (Out of compulsion and love), } \\
50 \% \text { likes are from friends with whom I talk regularly and the rest } 30 \% \text { is from the } \\
\text { teachers/ mentors }\end{array}$ \\
\hline
\end{tabular}

\section{Conclusions}

\section{Research Question 1}

Why does one 'like' a profile picture, cover photo or a post on timeline/ status update on facebook?

The reasons why a facebook user likes a post are exhaustive in this study. A facebook user likes a post to justify need for association through liking emotional and rational posts of facebook profiles/friends. A survey will be carried out to identify clusters and validate the types of likes across hierarchy of need for association.

\section{Research Question 2}

What gets more 'likes': profile picture, cover photo, or post on timeline/ status update? And why?

From the depth interviews and facebook profiles, it is evident that pictures posts garner more likes than textual posts. Among the profile picture, cover photo and status update, the profile picture catches maximum attention and gets maximum likes, followed by status update pictures, status update texts and then cover photos. The facebook user who posts plays a significant role in eliciting likes from friends on facebook. The reasons and number of likes are mostly based on multiple factors and could be generalisable based on need for association types 
via emotional and rational content. The responses are an interplay of emotion and reason that could vary with each situation.

\section{Research Question 3}

What are the different types of likes? Are there a standard proportion of types of likes for each post?

Each facebook user can identify a pattern among the types of likes across posts. A survey to validate the broad pattern will be carried out. Thus emerging pattern will be useful for marketers to assess the value of likes. 


\section{References}

An Exhaustive Study of Twitter Users across the World. (2012). Retrieved on May 28, 2014 from http://www.beevolve.com/twitter-statistics/\#a3

Budhiraja, S., \& Mhatre, D. (2011). Facebook Fan pages in India: Likes are not skin deep. WARC. Retrieved from http://www.warc.com/Content/ContentViewer.aspx?Master ContentRef=65b46bce-662f-4630b91a546f388a2ba6\&q=Facebook+Fan+pages + in + India+\%3a+Likes+are+not+skin+d eep\&CID=A97527\&PUB=ATTICUS

Bunker, M., Rajendran, K. N., \& Corbin, S. (2013).The antecedents of satisfaction for facebook "likes" and their effect on word of mouth. Marketing Management Journal, 23(2), 21-34.

Facebook Statistics. (2014). Retrieved on May 27, 2014 from http://www.statisticbrain.com/facebook-statistics/

friend. (n.d.). Online Etymology Dictionary. Retrieved May 04, 2015, from Dictionary.com website: http://dictionary.reference.com/browse/friend

Glossary of terms. Facebook help centre. Retrieved May 04, 2015, from Facebook website: https://www.facebook.com/help/219443701509174/

Increase your Facebook Likes (2013). Communication Briefings, 32(8), Jun 2013,6-6

Kincaid, J. (2009). Facebook activates 'like' button; Friend Feed tires of sincere flattery.

TechCrunch. Retrieved from http://techcrunch.com/2009/02/09/facebookactivateslike-button-friendfeed-tires-of-sincere-flattery/ on $29^{\text {th }}$ May 2014

like. (n.d.). Dictionary.com Unabridged. Retrieved on May 04, 2015, from Dictionary.com website: http://dictionary.reference.com/browse/like

Lipsman, A. , Mudd, G., Rich, M., \& Bruich , S. (2012).The power of "Like" how brands reach (and influence ) fans through social media marketing, Journal of Advertising Research, 52(1),40-52h

Mariani, R., \& Mohammed, D. (2014). "Like" A global endorsement. How clicking "Like" influences facebook users brand recall and future purchasing intentions, Journal of Management Policy and Practice, 15(4), 51-63

Maslow, A. (1943). A theory of human motivation, Psychological Review, 50, 370-396.

Murthy, P., Sharma, K., \& Shaikh, S. (2013). Vodafone: Giving new definitions to Facebook Likes. WARC. Retrieved from www.warc.com/Content/ContentViewer.aspx?Master ContentRef=2aecf220-103c 4e52-96cb-12802d9dd53\&q=Vodafone\%3aGiving+new+ definitions+to+Facebook + Likes \&CID=A99329\&PUB=WARC-PRIZE 
Nain, B. (2013). Nain's hierarchy of needs: An alternative to Maslow's and ERG's hierarchy of needs. Retrieved on May 2, 2015 from http://mpra.ub.uni-muenchen.de/47749/ MPRA paper No. 47749, posted on 24 June 2013 07:20 UTC

O'Connor, A. (2013). The Power of Popularity: An Empirical Study of the Relationship between Social Media Fan Counts and Brand Company Stock Prices. Social Science Computer Review, available at SSRN: http://ssc.sagepub.com/content/31/2/229. doi: $10.1177 / 0894439312448037$

Pelletier, M., \& Horky, A. (2013). The anatomy of a facebook like: An exploratory study of antecedents and outcomes. Nov 2013, 25, 207-208

Shoenberger, H., \& Tandoc, E. (2014). Understanding facebook use through explicit and implicit measures of attitudes and motivations. Online Journal of Communication and Media Technologies, 4(1).

Smith, C. (2014). By the Numbers: 105 Amazing Facebook User Statistics. Retrieved on May 27, 2014 from http://expandedramblings.com/index.php/by-the-numbers-17amazingfacebook-stats/\#.U4RCAXY9WSo

Twitter Statistics. (2014). Retrieved on May 27, 2014 from http://www.statisticbrain.com/twitter-statistics/

Wallace, E., Buil, I., de Chernatony, L., \& Hogan, M. (2014). Who " likes" You... and why? A Typology of Facebook Fans from "Fan" -atics and Self Expressives to Utilitarians and Authentics. Journal of Advertising Research, 54(1), Jun 2014, 92-109 